\title{
Comparison of microbial community structures in soils with woody organic amendments and soils with traditional local organic amendments in Ningxia of Northern China
}

\author{
Zhigang Li $^{\text {Equal first author, } 1}$, Kaiyang Qiu ${ }^{\text {Equal first author, } 1}$, Rebecca L. Schneider ${ }^{2}$, Stephen J. Morreale ${ }^{2}$, Yingzhong Xie ${ }^{\text {Corresp. } 1}$ \\ ${ }^{1}$ School of Agriculture, Ningxia University, Yinchuan, Ningxia, China \\ 2 Department of Nature Resources, College of Agriculture and Life Sciences, Cornell University, New York, New York, United States \\ Corresponding Author: Yingzhong Xie \\ Email address: xieyz@nxu.edu.cn
}

Background: Addition of organic amendments has been commonly adopted as a means to restore degraded soils globally. More recently, the use of woody organic amendments has been recognized as a viable method of capturing and retaining water and restoring degraded and desertified soil, especially in semi-arid regions. However, the impacts of woody amendments on soil microbial community structure, versus other traditional organic supplements is less understood.

Methods: Three locally available natural organic materials of different qualities, i.e. cow manure (CM), corn straw (CS), and chipped poplar branches (PB) were selected as treatments in Ningxia, Northern China and compared with control soils. Four microcosms served as replicates for each treatment. All treatments contained desertified soil; treatments with amendments were mixed with $3 \%(w / w)$ of one of the above organic materials. After 7 and 15 months from the start of the experiment, soil samples were analyzed for chemical and physical properties, along with biological properties, which included microbial $\alpha$-diversity, community structure, and relative abundance of microbial phyla.

Results: Both bacterial and fungal $\alpha$-diversity indices were weakly affected by amendments throughout the experimental period. All amendments yielded different microbial community compositions than the Control soils. The microbial community composition in the CS and PB treatments also were different than the CM treatment. After 15 months of the experiment CS and PB exhibited similar microbial community composition, which was consistent with their similar soil physical and chemical properties. Moreover, CS and PB also appeared to exert similar effects on the abundance of some microbial taxa, and both of these treatments yield different abundances of microbial taxa than the CM treatment.

Conclusion: New local organic amendment with PB tended to affect the microbial community in a similar way to the traditional local organic amendment with CS, but different from the most traditional local organic amendment with CM in Ningxia, Northern China. Moreover, the high C/N-sensitive, and lignin and cellulose decompose-related microbial phyla increased in CS and PB have benefits in decomposing those incorporated organic materials and improving soil properties. Therefore, we recommend that PB should also be considered as a viable soil organic amendment for future not in Ningxia, but also in other places. 
1 Comparison of microbial community structures in

2 soils with woody organic amendments and soils with

3 traditional local organic amendments in Ningxia of

4 Northern China

5

6 Zhigang Li ${ }^{1, \dagger}$, Kaiyang Qiu ${ }^{1, \dagger}$, Rebecca L. Schneider ${ }^{2}$, Stephen J. Morreale ${ }^{2}$ and Yingzhong Xie ${ }^{1}$ 7

$8{ }^{1}$ School of Agriculture, Ningxia University, Yinchuan, Ningxia, China

92 Department of Nature Resources, College of Agriculture and Life Sciences, Cornell University, 10 Ithaca, NY, USA

$\dagger$ These authors contributed equally to this work

13 Corresponding Author:

14 Yingzhong Xie

15 No. 489, West road of Helan Mountain, Xixia district, Yinchuan Ningxia, 750021, China.

16 E-mail address: xieyz@nxu.edu.cn 


\section{ABSTRACT}

Background: Addition of organic amendments has been commonly adopted as a means to restore degraded soils globally. More recently, the use of woody organic amendments has been recognized as a viable method of capturing and retaining water and restoring degraded and desertified soil, especially in semi-arid regions. However, the impacts of woody amendments on soil microbial community structure, versus other traditional organic supplements is less understood.

Methods: Three locally available natural organic materials of different qualities, i.e. cow manure (CM), corn straw (CS), and chipped poplar branches (PB) were selected as treatments in Ningxia, Northern China and compared with control soils. Four microcosms served as replicates for each treatment. All treatments contained desertified soil; treatments with amendments were mixed with $3 \%(\mathrm{w} / \mathrm{w})$ of one of the above organic materials. After 7 and 15 months from the start of the experiment, soil samples were analyzed for chemical and physical properties, along with biological properties, which included microbial $\alpha$-diversity, community structure, and relative abundance of microbial phyla.

Results: Both bacterial and fungal $\alpha$-diversity indices were weakly affected by amendments throughout the experimental period. All amendments yielded different microbial community compositions than the Control soils. The microbial community composition in the CS and PB treatments also were different than the CM treatment. After 15 months of the experiment CS and PB exhibited similar microbial community composition, which was consistent with their similar soil physical and chemical properties. Moreover, CS and PB also appeared to exert similar effects on the abundance of some microbial taxa, and both of these treatments yield different abundances of microbial taxa than the CM treatment.

Conclusion: New local organic amendment with PB tended to affect the microbial community in a similar way to the traditional local organic amendment with CS, but different from the most traditional local organic amendment with CM in Ningxia, Northern China. Moreover, the high $\mathrm{C} / \mathrm{N}$-sensitive, and lignin and cellulose decompose-related microbial phyla increased in CS and PB have benefits in decomposing those incorporated organic materials and improving soil properties. Therefore, we recommend that PB should also be considered as a viable soil organic amendment for future not in Ningxia, but also in other places.

\section{INTRODUCTION}


68 The incorporation of locally available organic materials into degraded soil has been a widely adopted practice. Organic amendments are recognized for their roles in increasing soil water holding capacity, soil porosity, and water infiltration and percolation, while decreasing soil crusting and bulk density (Thangarajan et al., 2013). Moreover, organic amendments stimulate soil microbial community growth and activity in degraded soils, resulting in mineralization of nutrients available to plants, and increasing soil fertility and quality (Luna et al., 2016). Based on their benefits of improving water status and soil fertility, organic amendments are extensively used in dry and desertified soils globally. In the arid and semi-arid regions of China and elsewhere, retaining and returning crop residues (e.g. wheat straw and corn straw) and adding livestock manure (e.g. cow manure, chicken manure, pig manure) to the soil have long been regarded as a practical and effective method for improving soil quality and crop productivity (Fan et al., 2014). However, a seldom employed strategy in these regions is the use of woody materials as a soil amendment technique, although there is much available materials that could be readily collected from more than 2.2 million $\mathrm{km}^{2}$ of shelterbelt forests extending across China (Dai \& Chu, 2010). More specifically, rapidly growing poplars (Populus alba and other members of the genus) are the most widespread and available tree throughout China (Jia et al., 2013). Moreover, in the highly degraded and desertified areas of Northern China, three-quarters of the poplar trees are planted as farmland shelterbelts (Jing et al., 2015). Within the seriously desertified Ningxia Autonomous Region, poplar species rank first among all trees and distribute through an area of $47,000 \mathrm{~km}^{2}$ (Sun et al., 2009).

Notably, our previous research has demonstrated that incorporation of as little as $2 \%$ wood chips $(\mathrm{w} / \mathrm{w})$ into the surface soil can effectively capture and retain more precipitation and improve soil physicochemical properties in Ningxia, China (Li et al., 2018). Additionally, we reported that wood chips presented several comparable benefits to traditional local amendments, such as crop straw and cow manure, in improving soil health and enhancing crop growth. Importantly, in contrast to rapidly decomposing compost materials, the incorporation of woody material in severely degraded soils can have valuable and long-lasting benefits due to its low decomposition rate (Weedon et al., 2009). However, the effects of wood chips as well as other traditional local organic amendments on soil microbial communities are insufficiently understood. Microbial communities are important for the functioning of the ecosystem, both in relation to direct interactions with plants, and with regard to nutrient and organic matter cycling (Adak \& Sachan, 2009). Moreover, microbial abundance, activity, and composition largely determine the sustainable productivity of agricultural land (van der Heijden et al., 2008), since microbes play an integral and essential role in all soil processes (Barrios, 2007). In particular, soil microbial communities play an important role in the $\mathrm{C}$ cycle and the metabolism of other 
103

104

105

106

107

108

109

110

111

112

113

114

115

116

117

118

119

120

121

122

123

124

125

126

127

128

129

130

131

132

133

134

135

136

137

138

nutrients, such as nitrogen for energy acquisition (Falkowski et al., 2018). Some scientists have reported that $\mathrm{C}$ addition seems to select for specific microbial groups that feed primarily on organic compounds, changing the composition of the microbial community (Zhong et al., 2010; Hu et al., 2012). But other studies also indicated that a change in microbial community structure does not always involve a change in microbial community function or an increase in availability of plant nutrients and crop productivity (Franco-Otero et al., 2012; Lazcano et al., 2013). Nevertheless, a series of studies have focused on exploring the functions of microorganism in soil process, and they have reported the ecological roles some microorganisms are playing in soils, including C, N and other nutrient cycling (Fierer et al., 2007, 2012; Hartmann et al., 2015; Zhang et al., 2018). These previous studies are useful for us to speculate what ecological roles microorganisms may play in our soil organic amendments, because wood decomposition processes are related to microorganisms in the soil (Sariyildiz et al., 2005) and those microorganisms, in turn, affect soil nutrient cycling (Wutzler et al., 2017). In addition, soil microbial parameters can react rapidly to changes in soil management (Gil-Sotres et al., 2005), and shortly after application of organic amendments, fast increases in soil microbial biomass and activity have been observed (Dinesh et al., 2010). For all of these reasons, it is important for us to assess short-term effects of our soil organic amendments via the reaction of microbial communities.

Previous studies also have indicated that $\mathrm{pH}$ and organic $\mathrm{C}$ were two major soil properties that drive soil microbial communities (Hollister et al., 2010; Liu et al., 2014). In this context, we assume that exogenous $\mathrm{C}$ input, such as organic amendments, would substantially influence microbial communities in soils. Moreover, woody materials and crop straw have more lignin and carbon $(\mathrm{C})$ content, and a higher $\mathrm{C}$ : nitrogen $(\mathrm{N})$ ratio than livestock manures, which makes them more difficult to decompose, so we hypothesize that they also differently affect soil microbes relative to manure, and other short-lived organic amendments. This contention is supported in other studies that indicated that organic amendments with a high C:N ratio resulted in higher microbial biomass and activity, and also displayed differences in microbial composition, compared to materials with low C:N ratio (Heijboer et al., 2016). Nevertheless, we know little about the effects of all local organic amendments, such as cow manure, corn straw, and poplar branches, on soil microbiota in degraded and desertified soils such as those in Ningxia, China. Better understanding of the microbial processes that take place in soils that have been treated with organic amendments could help identify the main drivers determining nutrient availability in order to improve soil health and facilitate crop growth. Therefore, in this context, in pursuit of the overall goal of our study, we employed an Illumina sequencing approach of bacterial and fungal ribosomal markers to compare the effects on soil microbiota of the addition of new woody amendments and the addition of traditional local amendments. The detailed objectives of this

Peer] reviewing PDF | (2019:01:34038:2:0:NEW 8 Mar 2019) 
139

140

141

142

143

144

145

146

147

148

149

150

151

152

153

154

155

156

157

158

159

160

161

162

163

164

165

166

167

168

169

170

171

172

study were to (a) compare soil amendments of poplar chips versus traditional organic amendments, including cow manure and corn straw, and their impacts on soil microbial $\alpha$ diversity and community composition,; (b) reveal the different effects of local organic amendments on specific microbial taxa; (c) determine the relationships between soil properties and soil microbial $\alpha$-diversity, community composition and specific microbial taxa, respectively.

\section{MATERIAL \& METHODS}

\section{Study Site}

A microcosm experiment was conducted for 15 months from April 2015 to July 2016 in a greenhouse in the Yinchuan Belly Desert, which is located at the eastern foot of the Helan Mountains in Ningxia Hui Autonomous Region, China (106 $08^{\prime} \sim 107^{\circ} 22^{\prime}$ E, $\left.38^{\circ} 28^{\prime} \sim 38^{\circ} 42^{\prime} \mathrm{N}\right)$. The characteristics of the study site are representative of those associated with the ongoing desertification processes throughout Northern China. Historically, the native landscape was grasslands, but it has been desertified after centuries of agriculture. Currently, the region is characterized by shifting dunes with scattered farmland shelterbelt forests, which along with the farmlands are supported by extensive irrigation. The elevation is $1,115 \mathrm{~m}$ above mean sea level and the region is characterized by a temperate continental climate, with $181.2 \mathrm{~mm}$ average annual precipitation and $1882.5 \mathrm{~mm}$ mean annual evaporation. The annual average temperature is $10.1{ }^{\circ} \mathrm{C}$, with a maximum of $37.2{ }^{\circ} \mathrm{C}$ in July, and a minimum of $-27.9{ }^{\circ} \mathrm{C}$ in January. The average wind speed is $1.6 \mathrm{~m} \mathrm{~s}^{-1}$ and the frostless period is $160-170$ days each year. The particle size distribution of soils is $92.5 \%$ sand (size $<2 \mathrm{~mm}$ ), $5.5 \%$ silt, and $2.0 \%$ clay. The soil chemical properties are listed in Table S1.

\section{Material Collection and Preparation}

The base soils for this experiment were collected at the study site. After collection, soils were sifted through a sieve with a mesh diameter of $2 \mathrm{~mm}$ and were air-dried before mixing with the selected organic materials or being used as control soils. Woody materials were obtained from pruned branches from a locally abundant poplar species (Populus alba L.), and herbaceous materials consisted of straw residues collected from local corn (Zea mays L.) after harvesting. Poplar branches and corn straw were air-dried, then ground to lengths of about $0.5 \mathrm{~cm}$. Cow manure, collected from a local dairy, was also air-dried and sieved through a screen with a mesh diameter of $0.5 \mathrm{~cm}$ to remove coarse material. The chemical properties of organic materials are also listed in Table S1. 


\section{Experimental Design}

175

Four treatments were tested in this study, including 1) the Control with desertified soil only, and soil treatments with incorporated organic material (3\%w/w), including: 2) 3\% cow manure (CM); 3) 3\% corn straw (CS); and 4) 3\% poplar branch (PB). Organic materials were added to the base soil and then mixed fully. For example, the soil mixture of $3 \%$ corn straw was created by adding $300 \mathrm{~g}$ corn straw (dry weight) to $9700 \mathrm{~g}$ base soil (dry weight) and mixing completely. Within the continuum of amendments, these proportions represented the minimum requirements for soil water retention, which was tested in a previous set of our experiments (Li et al., 2018).

Control soil and soil mixtures were placed in buckets with top and bottom diameter of 31.5 $\mathrm{cm}$ and $26.0 \mathrm{~cm}$, respectively, a height of $31.5 \mathrm{~cm}$. All buckets had small drainage holes at the bottom. Twelve kilograms of each soil mixture (base soil $+3 \%$ incorporated material) was packed in each bucket, after which $5 \mathrm{~g}$ of urea $\left(\mathrm{CO}\left(\mathrm{NH}_{2}\right)_{2}\right)$ and $2 \mathrm{~g}$ of monopotassium phosphate $\left(\mathrm{KH}_{2} \mathrm{PO}_{4}\right)$, dissolved into solution, were added to each bucket prior to the experiment. In order to supply basic nutrient requirement for alfalfa growth, the required amounts of urea and monopotassium phosphate added to the bucket were based on the results of our previous studies (Li et al., 2018). Initially, 12 plump alfalfa seeds were sowed in each bucket, but after the first month, only the six most robust seedlings were kept growing for the remainder of the experiment. Alfalfa was selected because it is an indicator plant in our study region. In all, 4 treatments $\times 4$ replicates (buckets) $\times 2$ times $(7$ months and 15 months $)=32$ buckets were set up and arranged in a randomized block design in a greenhouse. Throughout the whole experiment, soil moisture of all buckets was monitored based on weight. All buckets were watered once every ten days and were maintained at an approximately constant water content equal to about $70 \%$ of the water holding capacity of the Control. The indoor greenhouse temperature was maintained at $15-20^{\circ} \mathrm{C}$ from November to the following March, and $20-35^{\circ} \mathrm{C}$, from April to October during the experimental period.

\section{Soil sampling and nutrient measurements}

All 32 buckets were divided into two successive batches with 16 buckets, including four treatments with four replicates, in each batch. For each batch, the length of time before the measurements was based on the precise alfalfa flowering stage. The analyses of the first batch of 16 buckets were conducted when the alfalfa first flowered and was harvested in October 2015 (seven months after the start of the experiment), while the second set of measurements were conducted in July 2016 ( 15 months after the beginning of the experiment) when the alfalfa was harvested after flowering for a second time. After plants were harvested, soil from each entire 
208

209

210

211

212

213

214

215

216

217

218

219

220

221

222

223

224

225

226

227

228

229

230

231

232

233

234

235

236

237

238

239

240

241

242

bucket was mixed with a sterile shovel. Then a portion was collected, air dried, and sieved through a sieve with the mesh diameter of $0.5 \mathrm{~mm}$ for chemical analysis, while another portion was placed in a sterile plastic bag, transported to the laboratory on ice, and then sieved (2-mmmesh sieve) and stored at $-80^{\circ} \mathrm{C}$ for DNA extraction and later analysis of other biological property.

Soil organic C (SOC) was measured with the $\mathrm{K}_{2} \mathrm{Cr}_{2} \mathrm{O}_{7}-\mathrm{H}_{2} \mathrm{SO}_{4}$ oxidation method of WalkleyBlack (Nelson et al., 1996); total N (TN) was analyzed using the Kjeldahl procedure (ISSCAS, 1978); Alkaline-hydrolyzable (AN) was determined by an alkaline diffusion method (ISSCAS 1978); total $\mathrm{P}$ (TP) was determined using $\mathrm{H}_{2} \mathrm{SO}_{4}+\mathrm{HClO}_{4}$ digestion (Olsen et al., 1982); available $\mathrm{P}$ (AP) was extracted with $0.5 \mathrm{~mol} \mathrm{l}^{-1} \mathrm{NaHCO}_{3}(\mathrm{pH} \mathrm{8.5)}$ (ISSCAS, 1978); total K (TK) was determined following the Cornfield method (Kundsen et al., 1982); and available K (AK) was determined using a $\mathrm{CH}_{3} \mathrm{COONH}_{4}$ extraction method (Tran \& Simard, 1993). Microbial C (MBC) and $\mathrm{N}(\mathrm{MBN})$ were estimated by the fumigation-extraction method (Vance et al., 1987). Above data were listed in Table S2.

\section{DNA extraction, PCR amplification, and Illumina sequencing} Samples were separately tested at each sampling date. The total DNA was extracted from $0.5 \mathrm{~g}$ homogenized soil per sample using a Power Soil ${ }^{\mathrm{TM}}$ DNA Isolation Kit (MOBIO Laboratories, Carlsbad, CA, USA) following the manufacturer's instructions. A total of 16 extracted DNA samples, at each sampling date, were quantified using a Nanodrop-1000 spectrometer (NanoDrop Technologies, Wilmington, DE, USA) and diluted to a final concentration of $10 \mathrm{ng}$ $\mu \mathrm{L}^{-1}$. We used the universal primers 515F 5'- GTGCCAGCMGCCGCGGTAA -3' and 909R 5'CCCCGYCAATTCMTTTRAGT -3' that target the V4-V5 regions of the 16S rRNA bacterial gene and produce accurate phylogenetic information (Weisburg et al., 1991). For fungi, the ribosomal ITS region was amplified using primers ITS1F: 5'-

CTTGGTCATTAGAGGAAGTAA-3' (Gardes \& Bruns, 1993) and ITS2R: 5'GCTGCGTTCTTCATCGATGC-3' (White et al., 1990). To simultaneously analyze several samples in a single sequencing run, the $5^{\prime}$ end of the forward primer was fused with a $12 \mathrm{bp}$ different barcode sequence to a single sample. Each $25 \mu \mathrm{L}$ PCR reaction contained $10 \mathrm{ng}$ extracted DNA as a template, $\mathrm{Mg}^{2+}$-free PCR buffer, $3 \mathrm{mM} \mathrm{MgCl} 2,200 \mathrm{mM}$ dNTP, $200 \mathrm{nM}$ forward primer, $200 \mathrm{nM}$ reverse primer, and 1 unit of PrimeSTAR Max DNA Polymerase (Takara, Dalian, China). The thermal cycling protocol was $95^{\circ} \mathrm{C}$ for $2 \mathrm{~min}$ as the first step, followed by 30 cycles of PCR at $95{ }^{\circ} \mathrm{C}$ for $15 \mathrm{~s}$, at $57^{\circ} \mathrm{C}$ for $15 \mathrm{~s}$, and at $72{ }^{\circ} \mathrm{C}$ for $40 \mathrm{~s}$, and a final 10 -min extension at $72{ }^{\circ} \mathrm{C}$. All the amplicons were run in a $1 \%$ agarose gel $(\mathrm{w} / \mathrm{v})$, and the separated bands of the appropriate length were excised from the gel and purified using a 
243

244

245

246

247

248

249

250

251

252

253

254

255

256

257

258

259

260

261

262

263

264

265

266

267

268

269

270

271

272

273

274

275

276

277

QIAquick Gel Extraction kit (QIAGEN GmbH, Hilden, Germany). Finally, high-throughput sequencing of the 16S rDNA and ITS rDNA genes were conducted using Illumina MiSeq, and 300 bp paired-end reads were generated (Nanjing Tree \& Cloud InfoTech Ltd., Nanjing, China). All the sequences have been deposited in the Sequence Read Archive (SRA) of NCBI under the accession number of SRP149652 for 16S rDNA and the accession number of PRJNA503750 for ITS rDNA.

\section{Post-run analysis for $16 \mathrm{~S}$ rDNA}

The raw data were processed using the UPARSE pipeline with default parameters for each of the following steps: (1) to sort those exactly matching the specific barcodes into different samples; (2) to merge the paired-end reads with FLASH; (3) to trim the adapters, barcodes, and primers, and to remove sequences shorter than $200 \mathrm{bp}$; (4) to perform a quality filter using $\mathrm{E}$ (the sum of the error probabilities) $>1$; and (5) to cluster operational taxonomic units (OTUs) using a 97\% identity threshold, discard singleton reads, and perform chimera filtering (http://drive5.com/uparse/) (Edgar, 2013). However, in order to compare relative difference between samples in downstream analyses, a randomly selected subset of 10,510 sequences were considered per bacteria community sample and 7,786 sequences per fungal community sample.

\section{Statistical analysis}

Indices of $\alpha$-diversity analysis (Shannon and Simpson indices) were carried out in Quantitative Insights Into Microbial Ecology (QIIME) on rarefied OTU tables (Dataset S1), which were obtained from the results of the high-throughput sequencing. Then, all data analyses were computed using the Vegan package in $\mathrm{R}$. In all tests, a $p$-value $<0.05$ was considered statistically significant. The differences of soil properties, microbial $\alpha$-diversity, and relative abundances of microbial taxa among amendments were tested using one-way ANOVA, followed by Tukey's post-hoc test. The statistical significances of the dissimilarities in the microbial community composition between all pairs of amendments were analyzed with permutational multivariate analysis of variance. Principal coordinate analysis (PCoA) based on the Bray-Curtis dissimilarity was used to visualize the distribution patterns of the microbial community. Distance-based redundancy analysis (dbRDA) (based on the Bray-Curtis dissimilarity) was used to estimate the proportion of variability in the microbial community composition caused by each of the selected soil properties, and marginal tests were performed to test the significance of each test. Pearson's correlation analysis was used to detect the relationships between soil properties and the means of $\alpha$-diversity, as well as soil properties and relative abundance of microbial taxa. 


\section{8 \\ RESULTS AND DISCUSSION}

279

280

281

282

283

284

285

286

287

288

289

290

291

292

293

294

295

296

297

298

299

300

301

302

303

304

305

306

307

308

309

310

311

312

\section{Effects of local organic amendments on microbial a-diversity}

It seems that previous studies have not achieved an agreement on the effect of organic amendments on soil microbial $\alpha$-diversity. Some studies reported an increase (Francioli et al., 2016; Sharma et al., 2017), some studies found a decrease (Montiel-Rozas et al., 2018), and some others found no effect on soil microbial $\alpha$-diversity after organic amendment (Zhang et al., 2018). Our study appears similar to the latter, in that we found organic amendments had weak effects on microbial $\alpha$-diversity, although there were some significant differences observed for in Shannon index values for fungi after 7 months (Table 1). Specifically, only the CM treatment had significantly lower fungal Shannon index values than CS after 7 months; there were no significant differences between other treatments. All other bacterial and fungal $\alpha$-diversity indices were not significantly influenced by amendment both after 7 months and after 15 months. Other researchers have concluded that it's difficult to draw robust inferences from the effect of organic amendments on soil microbial $\alpha$-diversity, in part because these metrics often have little power in explaining differences in community structure (Hartmann \& Widmer, 2006). Other studies also confirmed that microbial diversity is a highly complex parameter, and its measurement by diversity indices is usually less informative than qualitative community structure analysis (Bonilla et al., 2012). Our studies support those studies.

Similarly, the correlation analysis, between soil properties and microbial $\alpha$-diversity, also indicated that organic amendments had weak effects on $\alpha$-diversity, since there were only few soil properties that were significantly correlated based on Shannon or Simpson index values (Table 2). Nevertheless, we should acknowledge that some other soil properties that we did not determine in this study might impact $\alpha$-diversity as well. Meanwhile, we should also acknowledge that alfalfa growth affected microbial $\alpha$-diversity.

\section{Effects of local organic amendments on microbial community composition} Previous studies have indicated that even when microbial $\alpha$-diversity was unaffected, organic amendments have shown a strong influence on the soil microbial community composition (Bonilla et al., 2012). Similarly in this study, all local organic amendments exhibited different microbial community compositions than the Control at after both 7 and 15 months of study ( $p<$ 0.05) (Table 3). In addition, both CS and PB treatments had different bacterial and fungal community compositions than $\mathrm{CM}$ at both sampling times, which was probably linked to the different soil properties among these treatments (Table S2). However, the CS treatment exhibited different bacterial and fungal community composition than the PB treatment after 
313

314

315

316

317

318

319

320

321

322

323

seven months, but they had similar microbial community compositions after 15 months ( $p>$ 0.05). Reinforcing the link with soil properties, treatments CS and PB had dissimilar soil properties after seven months, but they became more similar after 15 months. For example, AK was higher in the CS treatment than in PB after seven months, but showed no significant difference by the time of the second sample. Similar findings were also documented by others (Zhang et al., 2018).

In our study, PCoA analysis also showed that microbial communities in all treatments were only weakly separated from each other after seven months (Figure 1A and Figure 1C). However, after 15 months, all communities in amendment treatments were clearly separated from the Controls, and CS and PB were clustered together for both the bacterial and fungal communities and separate from the CM and Control treatments (Figure 1B and Figure 1D).

In all, compared with the Control, all local organic amendments altered the microbial community composition, but in the non-traditional PB organic amendment, microbial community composition became similar to the traditional CS amendment only at a later stage. Notably, both CS and PB amendments had different effects on microbial community composition than the most common traditional organic amendment, CM. These differences were evident throughout the whole experimental period.

Distance-based RDA analysis showed that bacterial and fungal community compositions also were affected by different soil properties (Table 4). After seven months, $\mathrm{pH}$, SOC, and TN were the factors that drove changes in both soil bacterial community composition (explaining $20.4,9.7$, and $14.0 \%$ of the total variance, respectively) and fungal community composition (explaining 13.1, 9.2, 11.4\%, respectively). This result was similar to Hartmann et al. (2015). However, AK also exhibited a strong effect on fungal community composition, accounting for $9.3 \%$ of the total variance. But among all soil parameters, $\mathrm{pH}$ was the strongest factor that drove variation in both bacterial and fungal community compositions in the soil; this was like the findings of other studies (Lauber et al., 2009; Rutigliano et al., 2014). Even after 15 months, pH, SOC, TN, and TP affected both bacterial (explained 12.8, 10.1, 13.7, and 14.3\%, respectively) and fungal community composition (explained 9.0, 9.8, 9.5, 10.5, and 15.1\%, respectively) in the soil. For fungal community composition, AK was the most influential factor, explaining $15.07 \%$ of the total variance. Therefore, we conclude that the fungal community in the desertified soils in our study were more sensitive to AK than the bacterial community. Moreover, we also noted that TP became a stronger factor affecting soil microbial community composition at the later stage. But, in the broadest perspective, $\mathrm{pH}$, SOC and TN should be considered the most important factors driving microbial communities in this study, since they affected both bacterial and fungal communities throughout entire experimental period. 
349

350

351

352

353

354

355

356

357

358

359

360

361

362

363

364

365

366

367

368

369

370

371

372

373

374

375

376

377

378

379

380

381

382

383

Effects of local organic amendments on relative abundance of microbial phyla Although local organic amendments were applied for a relatively short time in this study, we found, nevertheless, that distributions of microbial phyla in each treatment had changed significantly (ANOVA, $p=0.001$ or $<0.001$ ) (Table S3). Moreover, we also found that all amendments induced changes in the abundance of some dominant bacterial and fungal phyla, compared to the Controls (Figure 2A and Figure 2B). In addition, changes in those dominant bacterial and fungal phyla among treatments were different between the two sampling times. This finding was also similar to Zhang et al. (2018), and we assume that these changes through time were related to qualities of incorporated organic materials, changes in soil properties and sampling seasons. Also, similar to other studies (Zeng et al., 2016; Lladó et al., 2017; Zeng et al., 2017), the dominant bacterial phyla of Proteobacteria, Actinobacteria, Acidobacteria, Bacteroidetes, and Firmicutes all were detected in our amended soil. Among all bacterial phyla, Proteobacteria was the most dominant and had higher abundance in treatments CS and PB, than in $\mathrm{CM}$ and the Control after 15 months $(p<0.05)$. This result might be due to the reason that Proteobacteria is copiotrophic microorganism (Fierer et al., 2012) and a decomposer of lignin (Tian et al., 2015). However, Proteobacteria was negatively correlated with TP and AN, but positively correlated with SOC and MBC after 15 months (Table 5), which was probably because CS and PB enhanced the microbial activity and fixed more nutrients resulting in microbial growth in the microcosm buckets after 15 months. This was supported by the much higher MBC we observed in CS and PB treatments than in CM (Table S2). Furthermore, previous researchers also documented that organic amendments with a high $\mathrm{C}: \mathrm{N}$ ratio resulted in a higher microbial biomass and activity (Heijboer et al., 2016).

Similarly, Actinobacteria is also putatively identified as a group of copiotrophic taxawhich thrive in the condition of high $\mathrm{C}$ availability, and exhibit relatively rapid growth rates (Fierer et al., 2012). Our study supports this finding since the CM treatment, after 7 months, not only increased SOC and other soil nutrient contents (Table S2), but also increased abundance of Actinobacteria compared with the Control, (Figure 2A). In addition, after seven months Actinobacteria was also positively correlated with AN, AP and AK, but negatively correlated with $\mathrm{pH}$, (Table 5). Bacteroidetes is regarded as another group of typically copiotrophic taxa (Fierer et al., 2007), and have been found to be positively correlated with soil total P (Tian et al., 2015) and soluble P (Yashiro et al., 2016). In our study, Bacteroidetes had higher abundance in CM than in CS and PB treatments after 15 months (Figure 2B), but we did not find any soil nutrient that was correlated with this group (Table 5). Hence, we speculate that Bacteroidetes is slow-growing copiotrophic microorganism (Fierer et al., 2007), which reacted to soil nutrients too slowly to detect in our short-term study. 
384

385

386

387

388

389

390

391

392

393

394

395

396

397

398

399

400

401

402

403

404

405

406

407

408

409

410

411

412

413

414

415

416

417

418

419

Though after 15 months, Cyanobacteria also showed comparatively higher abundance in the treatment CM than CS and PB (but not significantly different from each other) (Figure 2B), this group is regarded as a $\mathrm{N}_{2}$-fixing microorganism common in soils and soil crusts (Antoninka et al., 2016; Rippin et al., 2018). Therefore, we assume that the higher values of TN and AN in CM relative to $\mathrm{CS}$ and $\mathrm{PB}$ could be the reason for higher abundance of Cyanobacteria found in $\mathrm{CM}$ (Table S2), although our correlation analysis did not detect this (Table 5).Nevertheless, Acidobacteria is regarded to be more adapted to a nutrient-limited soil environment (Ward et al., 2009; Fierer et al., 2012) and some scientists also characterize them as generally preferring soil environments with high carbon resource (Větrovský \& Baldrian, 2013). Our study also reinforces that viewpoint because after 15 months Acidobacteria was found in higher abundance in treatments CS and PB (Figure 2B), which contained lower available N, P, and K at that sampling time (Table S2). Furthermore, Acidobacteria was also negatively correlated with TP, AN, and AP in this study (Table 5). Gemmatimonadetes also showed copiotrophic features in this study, because a greater relative abundance was detected in the higher-nutrient treatment $\mathrm{CM}$ after seven months (Figure 2A). Correlation analysis also revealed that the relative abundance of Gemmatimonadetes was positively correlated with AN, AP, and AK (Table 5). Similarly, some previous studies support our findings (Bernard et al., 2007; Pfeiffer et al., 2013), yet little is known about the ecological roles of Gemmatimonadetes (Whitman et al., 2016). In contrast, both Planctomycetes and Chloroflexi were more abundant in treatments CS and PB than in CM after 7 months (Figure 2A). Similarly, correlation analysis also indicated that those two bacterial phyla were negatively correlated with some soil nutrients (Table 5). However, we assume that Planctomycetes were related to decomposition of CS and PB in soils, since Planctomycetes are regarded as the decomposers of organic matter, including cellulose and hemicellulose (Chapman et al., 2017; Ivanova et al., 2017). The high abundance of Chloroflexi may be a result of the accumulation of halogenated organic compounds generated during decomposition (Chapman et al., 2017).

Fungal phyla compositions were also different among treatments between the two sampling times (Figure 2C and Figure 2D). Though we know little about the ecological function of detected fungal phyla, some studies reported that the cellobiohydrolase gene is unique to fungi, broadly distributed in Ascomycota and Basidiomycota in forest soils, and encodes for an enzyme which is critical to cellulose breakdown (Edwards et al., 2011). Therefore, we assume that the higher relative abundance of Ascomycota (after 7 months), Basidiomycota (after both 7 and 15 months), and Zygomycota (after 7 months) detected in treatments PB and CS (Figure 2C and Figure 2D) could be correlated with the process of wood and straw decomposition in our treatments. Correlation analysis also showed that Ascomycota was positively correlated with $\mathrm{MBC}$, and Basidiomycota was positively correlated with $\mathrm{MBC}$ and $\mathrm{MBN}$, but both were 
420

421

422

423

424

425

426

427

428

429

430

431

432

433

434

435

436

437

438

439

440

441

442

443

444

445

446

447

448

449

450

451

452

negatively correlated with AN (Table 6). Hence, those fungal phyla might be accelerated to fix more AN and to decompose incorporated PB and CS in soils.

In addition, we consider the above fungi to play an essential role in incorporated organic material decomposition in the early stages, since some studies indicated that fungi were dominant litter decomposers at an early stage (Vořišsková \& Baldrian 2013; Žifč́ková et al., 2016), while bacteria were dominant decomposers at later stages (Berg, 2014). However, it is essential to acknowledge that we can only speculate on the ecological role of the detected taxa based on what has been previously described in other studies. Also, we only identified several organic amendment-sensitive bacteria and fungi to the level of phylum in this study. Therefore, a more in-depth analysis should also be conducted based on our data to find more information about specific microbial ecological roles. Moreover, long-term field studies should also be considered as the next important step. Importantly, we should acknowledge that alfalfa growth also likely affected the microbial community, although our main objective was to tease out the effects of different organic materials as soil amendment strategies.

\section{CONCLUSIONS}

In this study, we found that soil microbial $\alpha$-diversity reacted weakly to all local organic amendments. However, bacterial and fungal community compositions changed significantly for different amendments. Non-traditional organic amendments such as woodchips (treatment PB) exhibited similar effects to corn straw treatment (CS). Both PB and CS treatments influenced soil communities differently that the most traditional amendment using cow manure (CM). Soil organic carbon, total nitrogen and $\mathrm{pH}$ were the most important factors driving microbial community structure. In conclusion, woodchips should also be considered as a viable soil amendment for future applications.

\section{ACKNOWLEDGEMENTS}

We thank Drs. Xilu Ni, Changxiao Li and Jian Li for helping experimental design and data collection, and Dr. Tsafack Noelline for helping data analysis.

\section{REFERENCES}

Adak T \& Sachan RS. 2009. Effect of co-inoculation of Sinorhizobium meliloti and Bacillus megaterium on yield and nutrient uptake of fenugreek (Trigonella foenum-graecum L.) in Mollisol soil. Journal of Medicinal and Aromatic Plant Sciences 31:124-130 DOI http://dx.doi.org/ 
453

454

455

456

457

458

459

460

461

462

463

464

465

466

467

468

469

470

471

472

473

474

475

476

477

478

479

480

481

482

483

484

485

486

487

488

489

490

491

492

493

Antoninka A, Bowker MA, Reed SC, Doherty K. 2016. Production of greenhouse-grown biocrust mosses and associated cyanobacteria to rehabilitate dryland soil function. Restoration Ecology 24: 324-335 DOI 10.1111/rec.12311

Barrios E. 2007. Soil biota, ecosystem services and land productivity. Ecological Economics 64: 269-285 DOI 10.1016/j.ecolecon.2007.03.004

Bernard L, Mougel C, Maron P-A, Nowak V, Lévêque Henault J. 2007. Dynamics and identification of soil microbial populations actively assimilating carbon from ${ }^{13} \mathrm{C}$-labelled wheat residue as estimated by DNA- and RNA-SIP techniques. Environ Microbiol 9: 752-764 DOI 10.1111/j.14622920.2006.01197.x

Berg B. 2014. Decomposition patterns for foliar litter - A theory for influencing factors. Soil Biology and Biochemistry 78: 222-232 DOI 10.1016/j.soilbio.2014.08.005

Bonilla N, Gutiérrez-Barranquero JA, Vicente AD, Cazorla FM. 2012. Enhancing Soil Quality and Plant Health Through Suppressive Organic Amendments. Diversity 4: 475-491. DOI 10.3390/d4040475

Chapman E, Cadilloquiroz H, Childers DL, Turetsky M R., Waldrop MP. 2017. Soil microbial community composition is correlated to soil carbon processing along a boreal wetland formation gradient. European Journal of Soil Biology 82: 17-26 DOI https://doi.org/10.1016/j.ejsobi.2017.08.001

Dai G \& Chu W. 2010. Analysis on the status of farmland shelterbelt resources in the three-north regions and corresponding strategies. Forest Resources Management 1: 27-32.

Dungait JAJ, Kemmitt SJ, Michallon L, Guo S, Wen Q, Brookes PC, Evershed RP. 2011. Variable responses of the soil microbial biomass to trace concentrations of 13C-labelled glucose, using 13CPLFA analysis. Eur J Soil Sci 62:117-126 DOI 10.1111/j.1365-2389.2010.01321.x

Edgar RC. 2013. Uparse: Highly accurate otu sequences from microbial amplicon reads. Nature Methods 10: 996-998 DOI 10.1038/NMETH.2604

Edwards IP, Zak DR, Kellner H, Eisenlord SD, Pregitzer KS. 2011. Simulated Atmospheric N Deposition Alters Fungal Community Composition and Suppresses Ligninolytic Gene Expression in a Northern Hardwood Forest. PLoS ONE 6, e20421. DOI:10.1371/journal.pone.0020421

Falkowski PG, Fenchel T, Delong EF. 2018. The microbial engines that drive Earth's biogeochemical cycles. Science 320:1034-1039 DOI 10.1126/science.1153213

Fan J, Yu G, Wang Q, Malhi SS, Li Y. 2014. Mulching effects on water storage in soil and its depletion by alfalfa in the loess plateau of northwestern china. Agricultural Water Management 138: 10-16 DOI 10.1016/j.agwat.2014.02.018

Fierer N, Bradford MA, Jackson RB. 2007. Toward an ecological classification of soil bacteria. Ecology 88:1354-1364 DOI 10.1890/05-1839

Fierer N, Lauber CL, Ramirez KS, Zaneveld J, Bradford MA, Knight R. 2012. Comparative metagenomic, phylogenetic and physiological analyses of soil microbial communities across nitrogen gradients. The ISME Journal 6:1007-1017 DOI 10.1038/ismej.2011.159

Francioli D, Schulz E, Lentendu G, Wubet T, Buscot F, Reitz T. 2016. Mineral vs. Organic amendments: Microbial community structure, activity and abundance of agriculturally relevant microbes are driven by long-term fertilization strategies. Frontiers in Microbiology 7: 1446 DOI 10.3389/fmicb.2016.01446 
494

495

496

497

498

499

500

501

502

503

504

505

506

507

508

509

510

511

512

513

514

515

516

517

518

519

520

521

522

523

524

525

526

527

528

529

530

531

532

Franco-Otero VG, Soler-Rovira P, Hernández D, López-de-Sá EG, Plaza C. 2012. Short-term effects of organic municipal wastes on wheat yield, microbial biomass, microbial activity, and chemical properties of soil. Biology and Fertility of Soils 48:205-216 DOI 10.1007/s00374-011-0620-y

Gardes M, Bruns TD. 1993. ITS primers with enhanced specificity for basidiomycetes-application to the identification of mycorrhizae and rusts. Molecular Ecology 2: 113-118 DOI 10.1111/j.1365294X.1993.tb00005.x

Gil-Sotres F, Trasar-Cepeda C, Leiros M, Seoane S. 2005. Different approaches to evaluating soil quality using biochemical properties. Soil Biol Biochem 37:877-887 DOI 10.1016/j.soilbio.2004.10.003

Hartmann M, Widmer F. 2006. Community structure analyses are more sensitive to differences in soil bacterial communities than anonymous diversity indices. Applied \& Environmental Microbiology 72: 7804-7812 DOI 10.1128/AEM.01464-06

Hartmann M, Frey B, Mayer J, Mäder P, Widmer F. 2015. Distinct soil microbial diversity under longterm organic and conventional farming. The ISME Journal 9: 1177-1194. DOI 10.1038/ismej.2014.210

Heijboer A, Berge HFMT, Ruiter PCD, Jørgensen HB, Kowalchuk GA, Bloem J. 2016. Plant biomass, soil microbial community structure and nitrogen cycling under different organic amendment regimes; a 15N tracer-based approach. Applied Soil Ecology 107: 251-260 DOI 10.1016/j.apsoil.2016.06.009

Hollister EB, Engledow AS, Hammett AJM, Provin TL, Wilkinson HH, Gentry TJ. 2010. Shifts in microbial community structure along an ecological gradient of hypersaline soils and sediments. ISME Journal 4: 829-838 DOI 10.1038/ismej.2010.3

Hu J, Lin X, Wang J, Dai J, Chen R, Zhang J, Wong MH. 2010. Microbial functional diversity, metabolic quotient, and invertase activity of a sandy loam soil as affected by long-term application of organic amendment and mineral fertilizer. J Soils Sediments 11:271-280 DOI 10.1007/s11368010-0308-1

Lazcano C, Gómez-Brandón M, Revilla P, Domínguez J. 2013. Short-term effects of organic and inorganic fertilizers on soil microbial community structure and function. Biology and Fertility of Soils 49: 723-733 DOI 10.1007/s00374-012-0761-7

Luna L, Pastorelli R, Bastida F, Hernández T, García C, Miralles I, Solé-Benet A. 2016. The combination of quarry restoration strategies in semiarid climate induces different responses in biochemical and microbiological soil properties Applied Soil Ecology 107: 33-47 DOI 10.1016/j.apsoil.2016.05.006

Liu J, Sui Y, Yu Z, Shi Y, Chu H, Jin J. 2014. High throughput sequencing analysis of biogeographical distribution of bacterial communities in the black soils of northeast china. Soil Biology and Biochemistry 70: 113-122 DOI 10.1016/j.soilbio.2013.12.014

Institute of Soil Science, Chinese Academy of Sciences (ISSCAS). 1978. Physical and Chemical Analysis Methods of Soils. China Shanghai Science Technology Press, Shanghai, pp 7-59.

Jia L, Liu S, Zhu L, Jianjun HU, Wang X. 2013. Carbon storage and density of poplars in china. Journal of Nanjing Forestry University 37:17.

Peer] reviewing PDF | (2019:01:34038:2:0:NEW 8 Mar 2019) 
533

534

535

536

537

538

539

540

541

542

543

544

545

546

547

548

549

550

551

552

553

554

555

556

557

558

559

560

561

562

563

564

565

566

567

568

569

570

571

572

Jing DW, Xing SJ, Du Z. 2015. Effects of water stress on physiological and biochemical characteristics of Populus $\times$ euramericana cv. 'Neva' seedlings. Journal of Arid Land Resources and Environment 29: 54-58.

Kundsen D, Peterson GA, Pratt PF. 1982. Lithium, sodium, and potassium. Methods of soil analysis. Part 2. Chemical and microbiological potassium. Methods of soil analysis. Part 2. Chemical and microbiological.

Lauber CL, Hamady M, Knight R, Fierer N. 2009. Pyrosequencing-based assessment of soil pH as a predictor of soil bacterial community structure at the continental scale. Applied and Environmental Microbiology 75: 5111-5120 DOI 10.1128/AEM.00335-09

Li Z, Schneider RL, Morreale SJ, Xie Y, Li C, Li J. 2018. Woody organic amendments for retaining soil water, improving soil properties and enhancing plant growth in desertified soils of Ningxia, China. Geoderma 310: 143-152 DOI 10.1016/j.geoderma.2017.09.009

Lladó S, López-Mondéjar R, Baldrian P. 2017. Forest soil bacteria: diversity, involvement in ecosystem processes, and response to global change. Microbiology and Molecular Biology Reviews 81:e0063-00016 DOI 10.1128/MMBR.00063-16

Montiel-Rozas MM, Domínguez MT, Madejón E, Madejón P, Pastorelli R, Renella G. 2018. Long-term effects of organic amendments on bacterial and fungal communities in a degraded Mediterranean soil. Geoderma 332, 20-28 DOI 10.1016/j.geoderma.2018.06.022

Nelson DW, Sommers LE, Sparks DL, Page AL, Helmke PA, Loeppert R H. 1996. Total carbon, organic carbon, and organic matter. Methods of Soil Analysis Part-chemical Methods, 961-1010.

Olsen SR, Sommers LE, Page AL. 1982. Methods of soil analysis. Part 2. Chemical and microbiological properties of Phosphorus. ASA Monograph. 9: 403-430.

Pfeiffer B, Fender A-C, Lasota S, Hertel D, Jungkunst HF, Daniel R. 2013. Leaf litter is the main driver for changes in bacterial community structures in the rhizosphere of ash and beech. Appl Soil Ecol 72: 150-160 DOI 10.1016/j.apsoil.2013.06.008

Rippin M, Borchhard N, Williams L, Colesie C, Becker B. 2018. Genus richness of microalgae and cyanobacteria in biological soil crusts from svalbard and livingston island: morphological versus molecular approaches. Polar Biology 41: 1-15 DOI 10.1007/s00300-018-2252-2

Rutigliano FA, Romano M, Marzaioli R, Baglivo I, Baronti S, Miglietta F, Castaldi S. 2014. Effect of biochar addition on soil microbial community in a wheat crop. European Journal of Soil Biology 60: 9-15 DOI 10.1016/j.ejsobi.2013.10.007

Sariyildiz T, Anderson JM, Kucuk M. 2005. Effects of tree species and topography on soil chemistry, litter quality, and decomposition in northeast turkey. Soil Biology Biochemistry 37: 1695-1706 DOI 10.1016/j.soilbio.2005.02.004

Sharma A, Kachroo D, Hardev Ram RP, Pooja Gupta Soni DJ, Malu Ram Yadav TY. 2017. Impact of different transplanting dates and nutrient sources on soil microbial population and grain yield of basmati rice (Oryza sativa L.) grown under SRI. International Journal of Current Microbiology \& Applied Sciences 6: 778-782.

Sun Y, Wang D X, Zhang H, Li ZG, Wei YF, Hu TH. 2009. Forest ecosystem services and their valuation of Ningxia area. Journal of Northwest A \& F University 37: 91-97. 
573

574

575

576

577

578

579

580

581

582

583

584

585

586

587

588

589

590

591

592

593

594

595

596

597

598

599

600

601

602

603

604

605

606

607

608

609

610

611

612

Thangarajan R, Bolan NS, Tian G, Naidu R, Kunhikrishnan A. 2013. Role of organic amendment application on greenhouse gas emission from soil. Science of the Total Environment 465: 72-96 DOI 10.1016/j.scitotenv.2013.01.031

Tian W, Wang L, Li Y, Zhuang K, Li G, Zhang J, Xiao X, Xi Y. 2015. Responses of microbial activity, abundance, and community in wheat soil after three years of heavy fertilization with manurebased compost and inorganic nitrogen. Agriculture, Ecosystems \& Environment 213:219-227 DOI 10.1016/j.agee.2015.08.009

Tran TS, Simard RR. 1993. Mehlich III-extractable elements. In: Carter, M.R. (Ed.), Soil Sampling and Methods of Analysis. Canadian Society Soil Science. Lewis Publishers, CRC Press, Boca Raton, FL, pp 43-49.

van der Heijden MGA, Bardgett RD, van Straalen NM. 2008. The unseen majority: soil microbes as drivers of plant diversity and productivity in terrestrial ecosystems. Ecology letters 11: 296-310.

Vance ED, Brookes PC, Jenkinson DS. 1987. An extraction method for measuring soil microbial biomass C. Soil Biology Biochemistry 19:703-707 DOI 10.1016/0038-0717(87)90052-6

Voříšková J, Baldrian P. 2013. Fungal community on decomposing leaf litter undergoes rapid successional changes. The ISME journal 7: 477 DOI 10.1038/ismej.2012.116

Ward NL, Challacombe JF, Janssen PH, Henrissat B, Coutinho PM, Wu M. 2009. Three genomes from the phylum acidobacteria provide insight into the lifestyles of these microorganisms in soils. Applied Environmental Microbiology 75: 2046-2056 DOI 10.1128/AEM.02294-08

Weedon JT, Cornwell WK, Cornelissen JH, Zanne AE, Wirth C, Coomes DA. 2009. Global metaanalysis of wood decomposition rates: a role for trait variation among tree species? Ecology Letters 12: 45-56 DOI 10.1111/j.1461-0248.2008.01259.x

Weisburg WG, Barns SM, Pelletier DA, Lane DJ. 1991. 16S ribosomal DNA amplification for phylogenetic study. Journal of Bacteriology 173: 697-703 DOI http://dx.doi.org/

White TJ, Bruns T, Lee S, Taylor JW. 1990. Amplification and direct sequencing of fungal ribosomal rna genes for phylogenetics. In: Innis MA, D.H. Gelfand, Sninsky JJ, White. TJ (eds) PCR protocols: A guide to methods and applications. Academic Press, New York, pp315-322

Whitman T, Pepe-Ranney C, Enders A, Koechli C, Lehmann J. 2016. Dynamics of microbial community composition and soil organic carbon mineralization in soil following addition of pyrogenic and fresh organic matter. The ISME Journal 10. DOI 10.1038/ismej.2016.68

Wutzler T, Zaehle S, Schrumpf M, Ahrens B, Reichstein M. 2017. Adaptation of microbial resource allocation affects modelled long term soil organic matter and nutrient cycling. Soil Biology Biochemistry 115: 322-336. DOI 10.1016/j.soilbio.2017.08.031

Yashiro E, Pintofigueroa E, Buri A, Spangenberg JE, Adatte T, Niculita Hirzel H, Guisan A, van der Meer JR. 2016. Local environmental factors drive divergent grassland soil bacterial communities in the western Swiss Alps. Applied Environmental Microbiology 82:6303-6316. DOI 10.1128/AEM.01170-16

Zeng Q, An S, Liu Y. 2017. Soil bacterial community response to vegetation succession after fencing in the grassland of China. Science of The Total Environment 609: 2-10 DOI 10.1016/j.scitotenv.2017.07.102

Peer] reviewing PDF | (2019:01:34038:2:0:NEW 8 Mar 2019) 
613

614

615

616

617

618

619

620

621

622

623
Zeng Q, Dong Y, An S. 2016. Bacterial community responses to soils along a latitudinal and vegetation gradient on the Loess Plateau, China. Plos One 11: e0152894 DOI 10.1371/journal.pone.0152894

Zhang Y, Hao X, Alexander TW, Thomas BW, Shi X, Lupwayi NZ. 2018. Long-term and legacy effects of manure application on soil microbial community composition. Biology and Fertility of Soils 54: 269-283. DOI 10.1007/s00374-017-1257-2

Zhong W, Gu T, Wang W, Zhang B, Lin X, Huang Q, Shen W. 2010. The effects of mineral fertilizer and organic manure on soil microbial community and diversity. Plant Soil 326:511-522 DOI 10.1007/s11104-009-9988-y

Žifčáková L, Větrovský T, Howe A, Baldrian P. 2016. Microbial activity in forest soil reflects the changes in ecosystem properties between summer and winter. Environmental microbiology 18: 288-301 DOI 10.1111/1462-2920.1302 


\section{Table $\mathbf{1}$ (on next page)}

Effects of organic amendments on $\alpha$-diversity of soil bacteria and fungi after durations of 7 and 15 months (mean $\pm \mathrm{SE}$ ).

$\mathrm{CS}=$ corn straw, $\mathrm{CM}=$ cow manure, $\mathrm{PB}=$ poplar branch. Means with different letters are significantly different with $p<0.05$ assessed by Tukey's HSD test. 
1

\begin{tabular}{|c|c|c|c|c|c|}
\hline \multirow{2}{*}{ Time } & \multirow{2}{*}{ Treatment } & \multicolumn{2}{|l|}{ Bacteria } & \multicolumn{2}{|l|}{ Fungi } \\
\hline & & Shannon & Simpson & Shannon & Simpson \\
\hline \multirow[t]{4}{*}{7 months } & Control & $8.07 \pm 0.62 \mathrm{a}$ & $0.94 \pm 0.03 \mathrm{a}$ & $3.94 \pm 0.48 \mathrm{ab}$ & $0.77 \pm 0.08 \mathrm{a}$ \\
\hline & $\mathrm{CM}$ & $7.96 \pm 0.24 \mathrm{a}$ & $0.98 \pm 0.00 \mathrm{a}$ & $3.58 \pm 0.06 \mathrm{~b}$ & $0.76 \pm 0.02 \mathrm{a}$ \\
\hline & $\mathrm{CS}$ & $8.96 \pm 0.12 \mathrm{a}$ & $0.99 \pm 0.00 \mathrm{a}$ & $4.83 \pm 0.23 \mathrm{a}$ & $0.89 \pm 0.02 \mathrm{a}$ \\
\hline & $\mathrm{PB}$ & $8.22 \pm 0.22 \mathrm{a}$ & $0.99 \pm 0.00 \mathrm{a}$ & $4.25 \pm 0.05 \mathrm{ab}$ & $0.89 \pm 0.01 \mathrm{a}$ \\
\hline \multirow[t]{4}{*}{15 months } & Control & $8.97 \pm 0.14 \mathrm{a}$ & $0.99 \pm 0.00 \mathrm{a}$ & $4.38 \pm 0.34 \mathrm{a}$ & $0.90 \pm 0.02 \mathrm{a}$ \\
\hline & $\mathrm{CM}$ & $8.75 \pm 0.35 \mathrm{a}$ & $0.99 \pm 0.01 \mathrm{a}$ & $5.46 \pm 0.26 \mathrm{a}$ & $0.95 \pm 0.01 \mathrm{a}$ \\
\hline & $\mathrm{CS}$ & $9.17 \pm 0.11 \mathrm{a}$ & $0.99 \pm 0.00 \mathrm{a}$ & $3.32 \pm 0.82 \mathrm{a}$ & $0.68 \pm 0.14 \mathrm{a}$ \\
\hline & $\mathrm{PB}$ & $9.11 \pm 0.10 \mathrm{a}$ & $0.99 \pm 0.00 \mathrm{a}$ & $4.77 \pm 0.61 \mathrm{a}$ & $0.91 \pm 0.03 \mathrm{a}$ \\
\hline
\end{tabular}

2 
Table 2 (on next page)

Correlations between microbial $\alpha$-diversity and soil properties

${ }^{*} p<0.05, * * p<0.01$ 
1

\begin{tabular}{llllllllllllll}
\hline Time & Microbiome & $\alpha$-diversity & $\mathrm{pH}$ & $\mathrm{SOC}$ & $\mathrm{TN}$ & $\mathrm{TP}$ & $\mathrm{TK}$ & $\mathrm{AN}$ & $\mathrm{AP}$ & $\mathrm{AK}$ & $\mathrm{MBC}$ & $\mathrm{MBN}$ \\
\hline 7 months & Bacteria & Shannon & 0.273 & 0.160 & -0.121 & -0.083 & -0.111 & -0.421 & -0.247 & -0.014 & 0.353 & 0.358 \\
& & Simpson & 0.232 & 0.164 & -0.261 & -0.446 & -0.314 & $-0.564^{*}$ & -0.449 & -0.232 & $0.634 * *$ & 0.430 \\
& \multirow{2}{*}{ Fungi } & Shannon & 0.164 & 0.340 & -0.064 & -0.287 & -0.184 & -0.348 & -0.325 & -0.185 & $0.649 * *$ & 0.480 \\
& & Simpson & 0.302 & -0.198 & -0.160 & -0.350 & 0.055 & -0.293 & -0.378 & -0.229 & 0.256 & -0.111 \\
\multirow{2}{*}{15 months } & \multirow{2}{*}{ Bacteria } & Shannon & -0.026 & -0.108 & 0.156 & 0.467 & -0.248 & 0.418 & 0.464 & $0.609^{*}$ & -0.284 & -0.188 \\
& & Simpson & 0.273 & 0.160 & -0.121 & -0.083 & -0.111 & -0.421 & -0.247 & -0.014 & 0.353 & 0.358 \\
& \multirow{2}{*}{ Fungi } & Shannon & 0.231 & $0.627^{* *}$ & 0.367 & 0.184 & 0.319 & -0.266 & 0.114 & 0.294 & 0.362 & $0.522^{*}$ \\
& & Simpson & 0.164 & 0.340 & -0.064 & -0.287 & -0.184 & -0.348 & -0.325 & -0.185 & $0.649 * *$ & 0.480 \\
\hline
\end{tabular}

2 


\section{Table 3(on next page)}

Pairwise comparison of soil microbial community composition under different organic amendments at different times

Pairwise comparisons were analyzed by multivariate permutational analysis of variance (PERMANOVA). Values represent the pseudo- $F$ ratio $(F)$ and the level of significance $(p)$ 
1

\begin{tabular}{|c|c|c|c|c|c|c|c|c|}
\hline \multirow{3}{*}{ Pairwise comparison } & \multicolumn{4}{|c|}{7 months } & \multicolumn{4}{|c|}{15 months } \\
\hline & \multicolumn{2}{|c|}{ Bacterial } & \multicolumn{2}{|c|}{ Fungi } & \multicolumn{2}{|c|}{ Bacterial } & \multicolumn{2}{|c|}{ Fungi } \\
\hline & $F$ & $p$ & $F$ & $p$ & $F$ & $p$ & $F$ & $p$ \\
\hline Control vs CM & 3.21 & 0.030 & 2.99 & 0.035 & 3.81 & 0.032 & 4.55 & 0.034 \\
\hline Control vs PB & 3.24 & 0.031 & 3.64 & 0.032 & 2.04 & 0.033 & 3.79 & 0.024 \\
\hline Control vs CS & 2.58 & 0.030 & 4.14 & 0.029 & 2.60 & 0.033 & 4.01 & 0.023 \\
\hline $\mathrm{CM}$ vs $\mathrm{PB}$ & 7.97 & 0.024 & 3.57 & 0.023 & 3.17 & 0.031 & 6.77 & 0.025 \\
\hline $\mathrm{CM}$ vs $\mathrm{CS}$ & 7.83 & 0.038 & 2.91 & 0.028 & 3.57 & 0.034 & 3.96 & 0.032 \\
\hline $\mathrm{PB}$ vs $\mathrm{CS}$ & 2.87 & 0.037 & 3.36 & 0.036 & 1.42 & 0.185 & 1.69 & 0.062 \\
\hline
\end{tabular}

2 


\section{Table 4 (on next page)}

Correlations between soil microbial community composition and soil properties

Values represent the estimation variance component (VC) that explained the distribution of microbial community composition are shown out of the bracket, and the corresponding levels of significance $(p)$ are shown in the bracket. Values at $p<0.05$ are shown in bold. 
1

\begin{tabular}{|c|c|c|c|c|}
\hline \multirow{2}{*}{$\begin{array}{l}\text { Soil } \\
\text { properties }\end{array}$} & \multicolumn{2}{|l|}{7 months } & \multicolumn{2}{|l|}{15 months } \\
\hline & Bacteria & Fungi & Bacteria & Fungi \\
\hline $\mathrm{pH}$ & $20.45(0.001)$ & $13.05(0.005)$ & $12.83(0.008)$ & $8.96(0.021)$ \\
\hline $\mathrm{SOC}$ & 9.73(0.024) & $9.20(0.038)$ & $10.12(0.012)$ & $9.84(0.040)$ \\
\hline $\mathrm{TN}$ & $13.98(0.012)$ & 11.44(0.012) & $13.74(0.002)$ & $9.53(0.041)$ \\
\hline $\mathrm{TP}$ & $5.49(0.195)$ & $5.31(0.420)$ & $14.30(0.003)$ & $10.49(0.009)$ \\
\hline TK & $3.42(0.554)$ & $4.38(0.648)$ & $6.86(0.138)$ & $4.43(0.538)$ \\
\hline AN & $6.18(0.152)$ & $6.62(0.209)$ & $5.34(0.221)$ & $5.07(0.374)$ \\
\hline AP & $6.07(0.139)$ & $5.37(0.413)$ & $3.72(0.572)$ & $4.01(0.712)$ \\
\hline $\mathrm{AK}$ & $6.43(0.130)$ & $9.34(0.038)$ & $3.86(0.579)$ & 15.07(0.011) \\
\hline $\mathrm{MBC}$ & $3.93(0.419)$ & $4.30(0.681)$ & $3.85(0.550)$ & $3.58(0.737)$ \\
\hline MBN & $3.92(0.496)$ & $4.52(0.670)$ & $3.19(0.733)$ & $4.21(0.625)$ \\
\hline
\end{tabular}

2 


\section{Table 5 (on next page)}

Correlations between relative abundance of major bacterial phyla and soil properties

Bolded bacterial phyla were detected significantly different in relative abundance among treatments. ${ }^{*} p<0.05,{ }^{* *} p<0.01$. 


\begin{tabular}{|c|c|c|c|c|c|c|c|c|c|c|c|}
\hline Time & Bacterial phyla & $\mathrm{pH}$ & $\mathrm{SOC}$ & $\mathrm{TN}$ & $\mathrm{TP}$ & TK & AN & AP & $\mathrm{AK}$ & $\mathrm{MBC}$ & $\mathrm{MBN}$ \\
\hline \multirow[t]{9}{*}{7 months } & Proteobacteria & 0.442 & -0.047 & -0.260 & -0.336 & -0.291 & -0.325 & $-0.515^{*}$ & -0.432 & 0.461 & 0.334 \\
\hline & Actinobacteria & $-0.544^{*}$ & 0.198 & 0.409 & 0.349 & 0.009 & 0.448 & $0.589^{*}$ & $0.629 * *$ & -0.449 & -0.187 \\
\hline & Firmicutes & $-0.530 *$ & 0.202 & 0.400 & 0.432 & 0.221 & $0.540 *$ & $0.673 * *$ & 0.411 & -0.453 & -0.407 \\
\hline & Bacteroidetes & 0.393 & 0.326 & 0.363 & 0.360 & 0.457 & 0.154 & 0.304 & $0.604 *$ & 0.036 & 0.256 \\
\hline & Cyanobacteria & -0.129 & -0.325 & -0.222 & -0.001 & 0.181 & 0.032 & -0.089 & -0.298 & -0.198 & -0.308 \\
\hline & Acidobacteria & $0.554 *$ & -0.017 & -0.321 & $-0.616 *$ & -0.239 & $-0.800 * *$ & $-0.718 * *$ & -0.396 & $0.680 * *$ & $0.571 *$ \\
\hline & Planctomycetes & 0.352 & -0.192 & -0.452 & $-0.540 *$ & -0.352 & $-0.566^{*}$ & $-0.670 * *$ & $-0.501 *$ & 0.416 & 0.348 \\
\hline & Chloroflexi & 0.354 & 0.051 & -0.282 & -0.319 & -0.372 & $-0.566 \%$ & $-0.576 *$ & -0.333 & 0.459 & 0.400 \\
\hline & $\begin{array}{l}\text { Gemmatimonadete } \\
\text { s }\end{array}$ & -0.483 & -0.130 & 0.135 & 0.343 & 0.063 & $0.648 * *$ & $0.615^{*}$ & $0.498 *$ & -0.495 & $-0.601 *$ \\
\hline \multirow[t]{9}{*}{15 months } & Proteobacteria & -0.406 & $0.700 * *$ & 0.342 & $-0.563 *$ & 0.218 & -0.466 & -0.469 & -0.072 & $0.680 * *$ & 0.000 \\
\hline & Actinobacteria & 0.259 & $-0.587 *$ & -0.412 & 0.302 & 0.011 & 0.247 & 0.248 & -0.078 & $-0.566^{*}$ & -0.031 \\
\hline & Firmicutes & -0.158 & -0.123 & 0.232 & $0.823 * *$ & 0.217 & $0.817 * *$ & $0.819 * *$ & 0.491 & -0.400 & 0.255 \\
\hline & Bacteroidetes & 0.238 & -0.235 & -0.060 & 0.440 & -0.404 & 0.356 & 0.393 & 0.181 & -0.304 & -0.135 \\
\hline & Cyanobacteria & $0.578 *$ & -0.400 & -0.467 & 0.172 & $-0.569^{*}$ & -0.048 & 0.022 & -0.216 & $-0.585 *$ & 0.015 \\
\hline & Acidobacteria & -0.031 & 0.164 & -0.119 & $-0.814 * *$ & 0.104 & $-0.718 * *$ & $-0.753 * *$ & -0.419 & 0.478 & -0.003 \\
\hline & Planctomycetes & 0.089 & 0.052 & 0.163 & -0.149 & 0.137 & -0.104 & -0.164 & 0.048 & 0.303 & 0.111 \\
\hline & Chloroflexi & -0.329 & 0.178 & 0.179 & $-0.502 *$ & 0.299 & -0.243 & -0.339 & -0.218 & 0.489 & -0.199 \\
\hline & Gemmatimonadetes & $0.652 * *$ & $-0.644 * *$ & $-0.646^{* *}$ & -0.125 & $-0.665 * *$ & -0.307 & -0.270 & -0.393 & -0.480 & -0.438 \\
\hline
\end{tabular}




\section{Table 6(on next page)}

Correlations between relative abundance of fungal phyla and soil properties

Bolded fungal phyla were detected significantly different in relative abundance among treatments. ${ }^{*} p<0.05, * * p<0.01$. 
1

\begin{tabular}{|c|c|c|c|c|c|c|c|c|c|c|c|}
\hline Time & Fungal phyla & $\mathrm{pH}$ & SOC & $\mathrm{TN}$ & $\mathrm{TP}$ & $\mathrm{TK}$ & AN & $\mathrm{AP}$ & $\mathrm{AK}$ & $\mathrm{MBC}$ & $\mathrm{MBN}$ \\
\hline 7 & Ascomycota & 0.425 & 0.279 & -0.205 & -0.284 & 0.025 & $-0.515^{*}$ & -0.483 & -0.454 & $0.665 * *$ & 0.382 \\
\hline \multirow[t]{4}{*}{ months } & Basidiomycota & 0.479 & 0.323 & 0.020 & -0.090 & -0.013 & $-0.588 *$ & -0.384 & 0.055 & $0.674 * *$ & $0.610 *$ \\
\hline & Zygomycota & 0.322 & 0.214 & -0.090 & -0.225 & -0.052 & -0.421 & -0.342 & -0.383 & 0.408 & 0.458 \\
\hline & Glomeromycota & 0.257 & $-0.527 *$ & -0.411 & -0.214 & -0.146 & -0.320 & -0.421 & -0.427 & -0.107 & -0.172 \\
\hline & Chytridiomycota & 0.284 & -0.028 & -0.260 & -0.284 & 0.025 & $-0.636 * *$ & -0.483 & -0.454 & 0.394 & 0.494 \\
\hline 15 & Ascomycota & 0.096 & 0.183 & -0.137 & -0.408 & -0.023 & -0.463 & -0.492 & $-0.598 *$ & 0.234 & 0.200 \\
\hline \multirow[t]{4}{*}{ months } & Basidiomycota & -0.155 & 0.423 & 0.153 & -0.231 & -0.172 & -0.223 & -0.241 & 0.062 & 0.331 & -0.167 \\
\hline & Zygomycota & -0.140 & 0.065 & 0.133 & -0.013 & -0.081 & 0.070 & 0.083 & $0.541 *$ & 0.070 & -0.217 \\
\hline & Glomeromycota & 0.356 & $-0.725 * *$ & $-0.634 * *$ & -0.129 & -0.179 & -0.238 & -0.216 & -0.412 & $-0.509 *$ & -0.321 \\
\hline & Chytridiomycota & 0.175 & -0.188 & -0.243 & -0.332 & -0.441 & -0.300 & -0.280 & 0.142 & -0.026 & -0.482 \\
\hline
\end{tabular}

2 
Figure 1

Principal coordinate analysis (PCOA) of microbial community composition.

(A)bacterial community after 7 months, (B) bacterial community after 15 months, (C) fungal community after 7 months, and (D) fungal community after 15 months. CS = corn straw, CM = cow manure, $\mathrm{PB}=$ poplar branch.
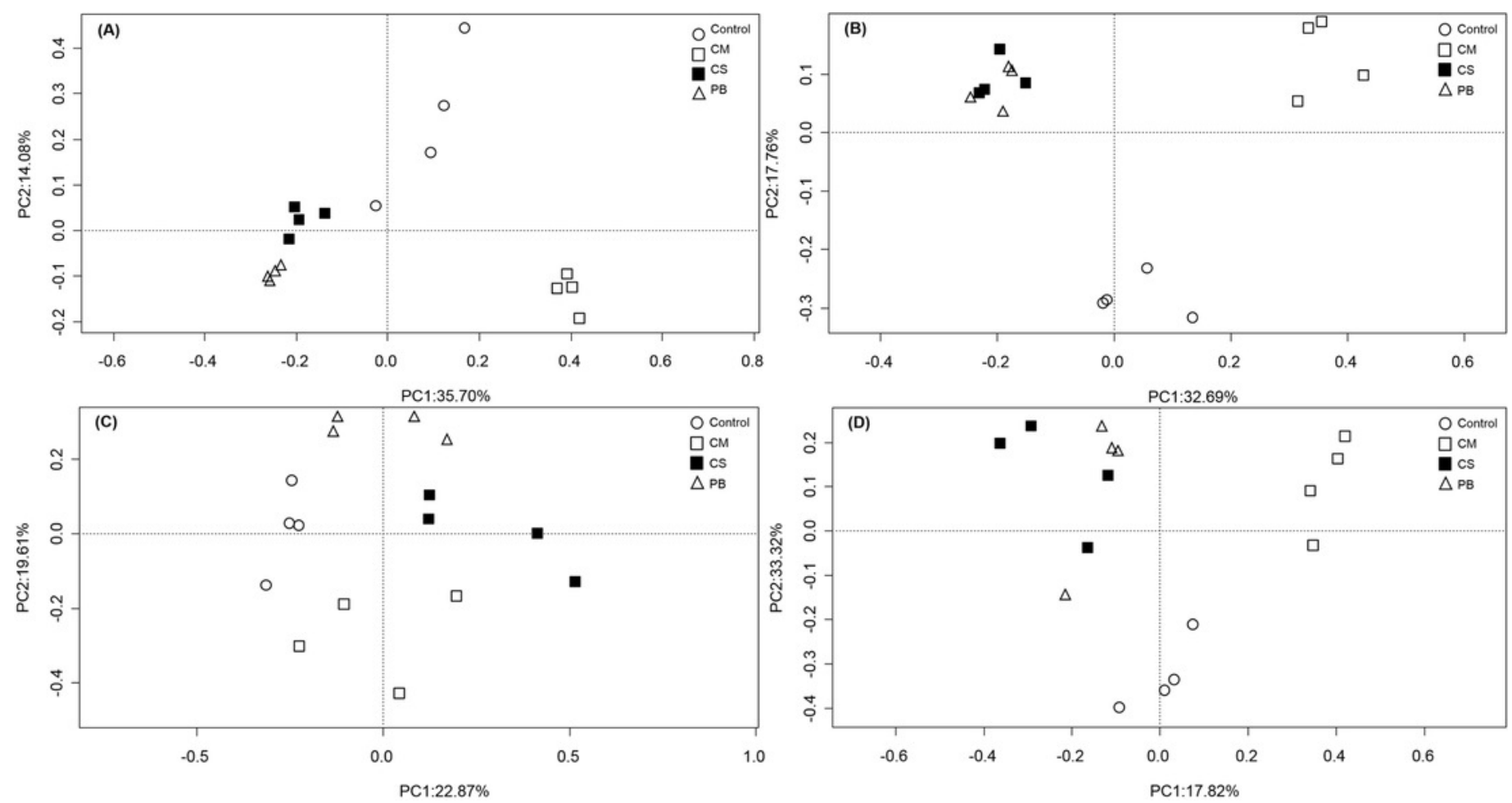


\section{Figure 2}

Relative abundance of the dominant microbial phyla.

(A)bacterial phyla after 7 months, (B) bacterial phyla after 15 months, (C) fungal phyla after 7 months, and (D) fungal phyla after 15 months. Different letters indicate significant differences based on Tukey's HSD test $(p<0.05) . \mathrm{CS}=$ corn straw, $\mathrm{CM}=$ cow manure, $\mathrm{PB}=$ poplar branch. Only the phyla with significantly different relative abundance among amendments were labelled with letters. Error bars represent standard error $(n=4)$.

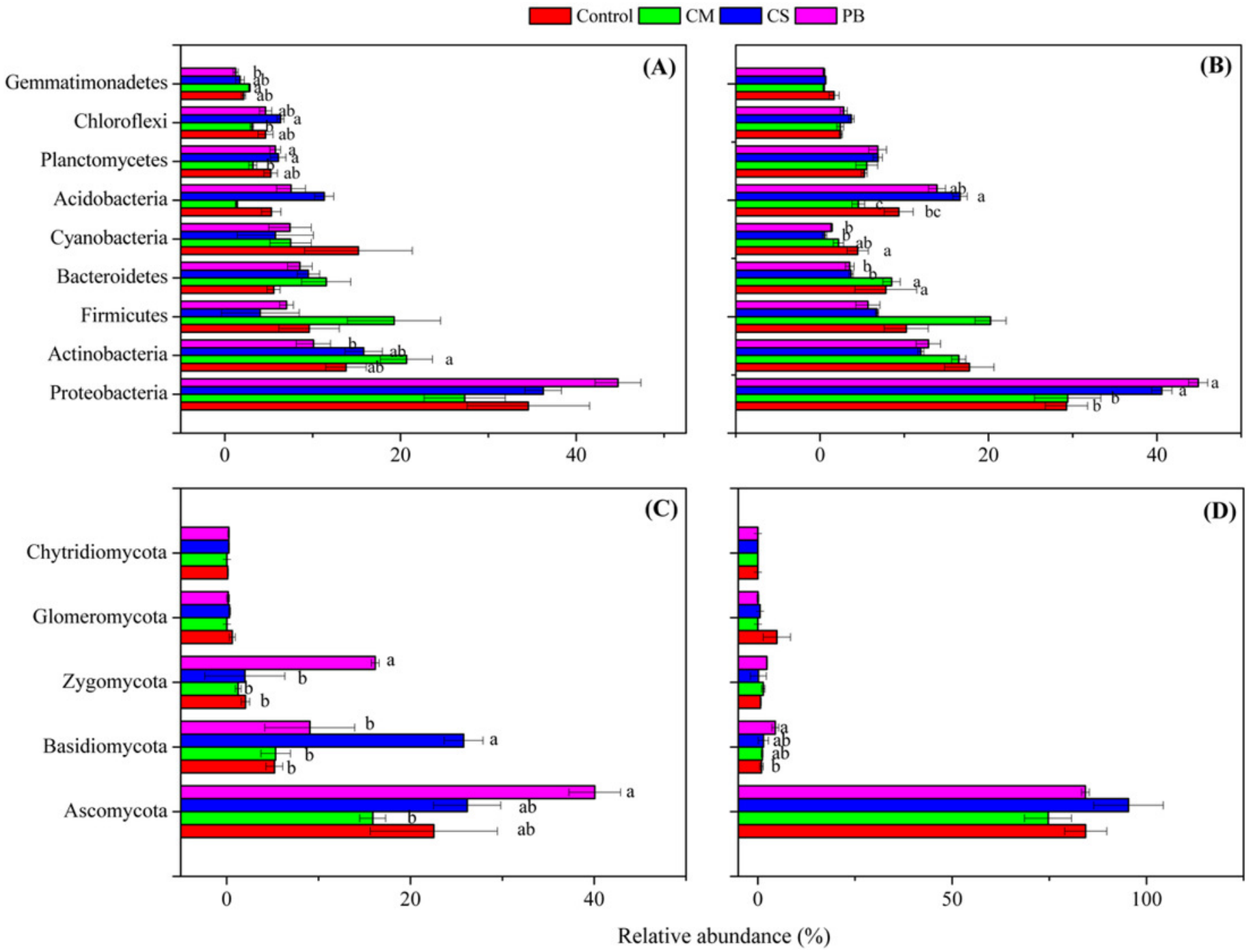

